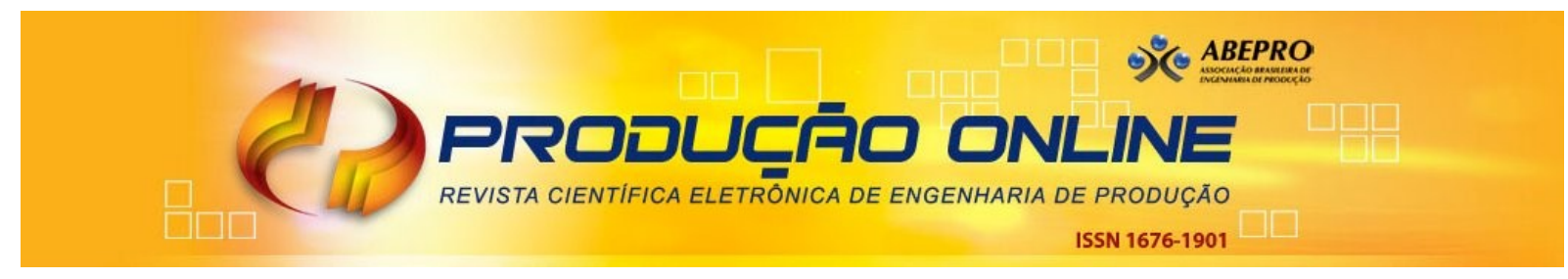

\title{
O PAPEL DA GESTÃO DE REQUISITOS EM PROJETOS DE AMBIENTES CONSTRUÍDOS: UM ESTUDO DE CASO
}

\section{THE ROLE OF REQUIREMENTS MANAGEMENT IN THE DESIGN OF BUILT ENVIRONMENTS: A CASE STUDY}

\author{
Camila Pegoraro*E-mail: camila pegoraro@yahoo.com.br \\ Tarcísio Abreu Saurin*E-mail: saurin@ufrgs.br \\ Istefani Carísio de Paula* E-mail: istefani@producao.ufrgs.br \\ * Universidade Federal do Rio Grande do Sul, UFRGS, Porto Alegre, RS
}

\begin{abstract}
Resumo: Frente às já conhecidas dificuldades na gestão dos projetos de ambientes construídos, pesquisadores e profissionais têm continuamente desenvolvido e aplicado boas práticas de áreas como a gestão de projetos (GP). Contudo, ainda há carências a serem supridas, como a dificuldade em acompanhar dinamicamente a evolução dos requisitos dos envolvidos. Na tentativa de suprimir esta lacuna, o artigo objetiva analisar se a gestão de requisitos (GR) pode ser integrada à GP de ambientes construídos, e quais as principais vantagens e desvantagens desta integração. A pesquisa contou com uma revisão teórica que trouxe conceitos básicos da GP e da GR, contando esta última com contribuições da engenharia de software. Também foi realizado um estudo de caso em uma empresa construtora, através de entrevistas semi-estruturadas. A pesquisa permitiu concluir que a utilização da GR é vantajosa, apesar de não solucionar todas as dificuldades dos projetos, e que a adequada estruturação dos projetos é um condicionante para o sucesso da GR. A principal contribuição é uma proposta genérica e sistemática para integrar as etapas da GR aos projetos.
\end{abstract}

Palavras-chave: Gestão de requisitos. Gestão de projetos. Ambientes construídos.

Abstract: Due to the known difficulties on managing the design process of built environments, researchers and entrepreneurs have continuously developed and implemented best practices from areas such as Project Management (PM). However, there are still gaps to be filled, such as difficulties on monitoring the stakeholder's requirements and their dynamics. In attempt to eliminate this gap, this paper aims to analyze if requirements management (RM) can be integrated to PM and which are the main advantages and disadvantages of this integration. The research includes a literature review which presents PM and RM concepts, the last one based on software engineering approach. Moreover, a case study was performed in a construction company, using semi-structured interviews. The research showed that the use of RM is advantageous, even not solving all the projects difficulties, and that the proper structuring of the projects is a condition for the success of RM implementation. The main contribution is a generic and systematic proposal for integrating the stages of the RM to the projects.

Keywords: Requirements management. Project management. Construction. 


\section{INTRODUÇÃO}

As empresas que desenvolvem projetos de edificações enfrentam problemas relativamente bem conhecidos no meio acadêmico e profissional, tais como as dificuldades na coordenação dos interesses dos intervenientes, no planejamento das atividades, na administração de recursos e no controle dos prazos (MELHADO, 2005; TZORTZOPOULOS, 2004). Considerando que melhorias nestes aspectos são essenciais para tais empresas se adequarem às exigências do mercado (PEKTAS e PULTAR, 2006), a partir da década de 90, mais enfaticamente, pesquisas tem buscado referências teóricas e práticas em outros setores. Alguns exemplos são a gestão de projetos (GP) (ROMANO, 2003) e a gestão de requisitos (GR) (MIRON, 2002, HUOVILA, 2005).

A GP consiste no planejamento e controle de uma série de tarefas que pretendem atingir os objetivos de todas as partes interessadas em um projeto (KERZNER, 2002). Muitos métodos são disponíveis na literatura (Methodware $\AA$; TenSetp $\AA$; PRINCE2 - Project in Controlled Enviroment, por exemplo) tendo eles alcançado nas últimas décadas patamares altos de detalhamento e disseminação em diferentes áreas (TURNER, 2010). Contudo, algumas carências ainda estão presentes nestes métodos, como a dificuldade em gerenciar as incertezas e mudanças (ATKINSON; CRAWFORD; WARD, 2006).

Em projetos de ambientes construídos as incertezas e mudanças de requisitos são inevitáveis, por motivos como o longo tempo de desenvolvimento, quantidade de intervenientes e complexidade do produto (SUN et al., 2005; SENARATNE; SEXTON, 2008). Frente à carência de práticas que acompanhem dinamicamente a evolução destes requisitos, os quais podem ser incluídos, excluídos, transformados ou desdobrados em cada fase do projeto, este artigo explora a GR como uma fonte de práticas para suprir esta lacuna.

Mesmo já tendo sido estudado no contexto da construção (SHEN et al., 2004; MIRON, 2008) o problema relacionado ao dinamismo dos requisitos ainda não está suprido. Diante disso, parte da revisão teórica foi feita sobre a produção de autores da engenharia de software, área na qual se pode encontrar conceitos e práticas de GR mais bem desenvolvidos. Para autores desta área, a GR objetiva viabilizar a Revista Produção Online. Florianópolis, SC, v.11, n. 4, p. 965-994, out./dez. 2011. 
identificação, análise, priorização, especificação e validação de requisitos ao longo do desenvolvimento dos projetos (WIEGERS, 2003; SOMMERVILLE, 2007), e, com isso, minimizar os impactos negativos das mudanças. Os mesmos autores afirmam que a GR traz benefícios aos projetos ao proporcionar o acompanhamento dos requisitos e acusação das incertezas, possibilitando a discussão e um melhor controle sobre as mudanças. Ainda, é importante destacar que, apesar de softwares serem produtos significativamente diferentes de edifícios em aspectos como custo e ciclo de vida, existe uma característica comum importante relacionada aos requisitos: tanto os softwares como os edifícios são produtos únicos, desenvolvidos sob medida sob determinadas circunstâncias, para determinados clientes.

Compreendido o contexto e o problema de pesquisa - a carência de práticas na GP que acompanhem dinamicamente a evolução dos requisitos - este artigo objetiva explorar se GR pode ser integrada à GP em projetos de ambientes construídos, e quais as principais vantagens e desvantagens desta integração. A principal contribuição é uma proposta genérica e sistemática para integrar as etapas essenciais da GR às da GP para suprir algumas dificuldades durante o desenvolvimento do projeto, como a rastreabilidade e o controle das mudanças dos requisitos.

\section{REVISÃO TEÓRICA}

Esta seção apresenta as principais informações encontradas na etapa de revisão teórica. Dentro de dois temas principais, a GP e a GR, foram estudados conceitos e práticas de autores da construção civil, e também de outras áreas, a fim de enriquecer as bases teóricas para o desenvolvimento desta pesquisa.

\subsection{Gestão de projetos (GP)}

Dentre outras definições, o PMBoK (PMI, 2004) afirma que um projeto é esforço temporário empreendido para criar um produto, um serviço ou um resultado. Um projeto é uma atividade que implica um prazo limitado, uma data definida para a conclusão e um resultado diferente daquele produzido no curso da rotina Revista Produção Online. Florianópolis, SC, v.11, n. 4, p. 965-994, out./dez. 2011. 
operacional de uma organização (KEELING, 2002). Este autor define algumas características e benefícios trazidos pela GP, dentre as quais se destacam:

- Simplicidade: metas e objetivos de fácil entendimento;

- Controle independente: pode ser protegido do mercado ou de outras flutuações que afetam as operações rotineiras;

- Maior facilidade de medição: o andamento do projeto pode ser medido por meio da comparação com metas e padrões definidos de desempenho;

- Flexibilidade de emprego: pode empregar ou agregar especialistas e peritos por períodos limitados;

- Útil ao desenvolvimento individual: trabalhar com uma equipe de projetos eficiente favorece ao desenvolvimento acelerado e a capacitação pessoal. Meredith e Mantel Jr. (2002) complementam a definição com mais algumas características:

- Desmembramento: Ao longo da execução, o projeto é, geralmente, desmembrado em subtarefas, buscando atingir os objetivos aos poucos, mas com mais eficácia;

- Interdependências: há uma interação freqüente entre os projetos de uma mesma organização, os quais também acabam interagindo com as atividades de rotina;

- Unicidade: todo projeto possui elementos únicos, alguns projetos podem ser similares, mas nunca iguais;

- Conflito: característica inerente ao projeto, quando há a necessidade de concorrer com os departamentos funcionais por recursos.

Segundo o PMI (2004) a gestão de um projeto envolve a execução de processos gerenciais de (a) iniciação, (b) planejamento, (c) execução, (d) monitoramente e controle e (e) encerramento, os quais estão resumidamente descritos a seguir e têm uma atuação no projeto conforme a Figura 1. 


\section{Figura 1 - Interação de grupos de processos em um projeto}

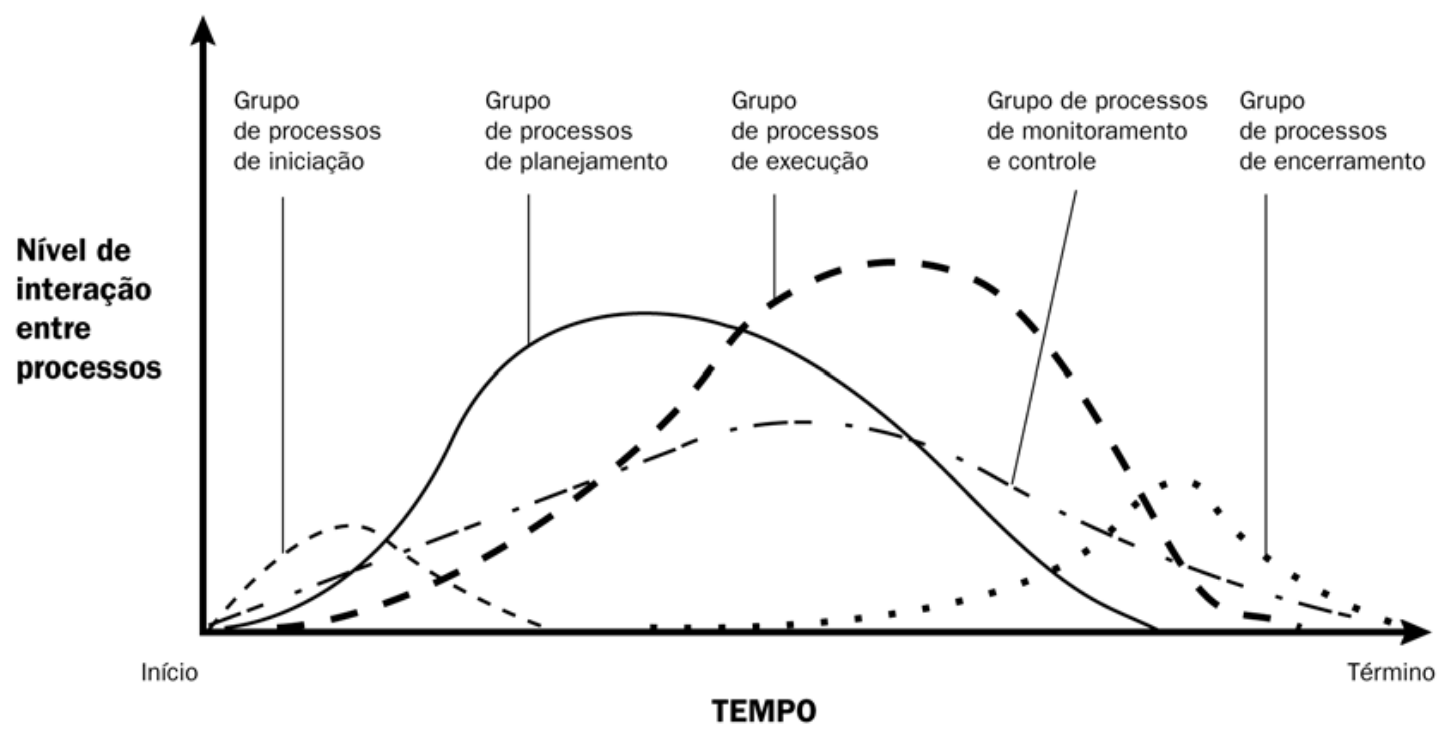

Fonte: PMI (2004)

a) Iniciação: fase na qual é definido o propósito do projeto e as necessidades para executá-lo.

b) Planejamento: nessa fase é definido e refinado o objetivo do projeto, as ações necessárias para atingir os objetivos são planejadas e também é determinado o escopo para o qual se propõe o projeto. Nessa fase são desenvolvidos planos auxiliares para gestão do projeto (qualidade, comunicação, riscos, por exemplo).

c) Execução: integra as pessoas e os outros recursos para colocar em prática o plano do projeto. É geralmente nessa fase em que ocorre a maior parte do esforço e dispêndio do projeto.

d) Monitoramento e Controle: ocorre em paralelo ao processo de execução. Mede, monitora e controla o progresso para identificar variações em relação ao planejado, para que ações corretivas sejam disparadas quando necessário.

e) Encerramento: formaliza a aceitação do projeto, serviço ou resultado. Analisa a evolução do projeto para que erros não se repitam no futuro. Encerra formalmente as relações entre os envolvidos.

Para implementar projetos, o PMI (2004) propõe ao logo das fases a ação integrada de nove áreas de conhecimento: gestão do escopo, tempo, custos, 
qualidade, recursos humanos, comunicação, riscos, aquisições e integração. Estas ações são gerenciadas pelo gerente de projetos, que é a pessoa responsável pela realização das atividades e atendimento dos objetivos (GUSMÃO et al., 2006). É de sua competência a identificação das necessidades; o estabelecimento de objetivos claros e alcançáveis; a aprovação de trade-offs; a alocação de pessoal e a adaptação dos planos diante de mudanças (PMI, 2004).

Os mecanismos de controle das mudanças de escopo da área de gestão do escopo e as práticas que asseguram a adequada gestão da informação na área de comunicação são as mais relevantes a esta pesquisa. Ao tratar da gestão do escopo, as práticas descritas no PMBoK (PMI, 2004), por exemplo, tratam da identificação e acompanhamento dos requisitos, contribuindo para a atualização do escopo do projeto. Já a gestão da comunicação é importante por determinar um padrão de qualidade para a troca de informação entre os envolvidos e facilitar as relações entre os mesmos. Algumas atividades relacionadas a requisitos estão pulverizadas nas diferentes áreas da GP.

Por fim, destaca-se que há vantagens em adotar os conceitos da GP para gerenciar os processos de projeto da construção civil, pois estes últimos deixam de ser tratados como as atividades de rotina. Apesar de os procedimentos e etapas serem repetitivos de um empreendimento para outro, existe a característica essencial da não repetição do mesmo projeto. A presença de elementos repetitivos não muda a singularidade fundamental do trabalho do projeto (PMI, 2004). Para Patah e Carvalho (2001), a conduta de tratar projetos como atividades de rotina compromete a organização, pois implica em prejuízos, como o desperdício de tempo e recursos.

\subsection{Gestão de requisitos (GR)}

A GR é uma abordagem que contribui no desenvolvimento de projetos por buscar estabelecer e manter a concordância entre o consumidor, a equipe de desenvolvimento e todos os demais envolvidos (SOMMERVILLE, 2007). A concordância deve existir tanto frente aos requisitos iniciais, quanto perante as mudanças que ocorrem no decorrer do tempo (KOTONYA; SOMMERVILLE, 2000).

Revista Produção Online. Florianópolis, SC, v.11, n. 4, p. 965-994, out./dez. 2011. 
Tais mudanças são inevitáveis (SUN et al., 2005) e quanto mais eficaz for a gestão dos requisitos, maior também a probabilidade de sucesso do projeto (BRAY, 2002). Miron (2008) destaca que a boa GR contribui para o delineamento mais claro dos resultados que se espera de um projeto, e facilita a identificação das habilidades e carências que tornam os envolvidos hábeis ou não a desenvolvê-lo.

$\mathrm{Na}$ construção civil usa-se também o termo briefing para denominar o processo de GR de um projeto (BARRET; STANLEY, 1999; SHEN et al., 2004; entre outros). Na visão tradicional, até meados da década de 90 , o briefing era uma atividade da concepção inicial do empreendimento, cujo objetivo era a elaboração de uma lista de necessidades a serem consideradas. No entanto, no final da década de 90 , firma-se a proposta de que o briefing é a maior fonte de comunicação entre os clientes e que deve acompanhar todo o projeto (BARRET; STANLEY, 1999; SHEN et al., 2004), quando os requisitos são progressivamente considerados e colocados em prática (HUOVILA, 2005). Esta nova abordagem deu origem ao briefing moderno que, basicamente, tem os mesmos conceitos e objetivos da GR, embora mais elementares.

Diante disto, para melhor embasar esta pesquisa, foram buscados conhecimentos na área da engenharia de software, pois é onde se encontra uma extensa e mais profunda produção ligada ao assunto. Apesar de softwares serem produtos distintos à edificação, e possuírem consideráveis diferenças no processo de desenvolvimento, no acesso à tecnologia da informação, na possibilidade de realização de testes e na própria capacitação dos profissionais em relação à GR, entende-se que é possível e válida a proposta de adaptação de algumas práticas.

Os autores pesquisados (KOTONYA; SOMMERVILLE, 2000; BRAY, 2002; YOUNG, 2003; WIEGERS, 2003; SOMMERVILLE, 2007), destacam que a GR tem um objetivo fundamental, e diferencial, diante de outras abordagens gerenciais: controlar as mudanças no projeto através do rastreamento dos requisitos, e gerenciá-las.

Para identificar requisitos é preciso que, primeiramente, os clientes do projeto sejam ouvidos para o levantamento de suas demandas (KAMARA; ANUMBA; EVBUOMWAN, 2002; SHEN et al., 2004; BRAY, 2002). Nesta pesquisa a definição de cliente é sinônima de stakeholder, ou seja, são todos os envolvidos em um Revista Produção Online. Florianópolis, SC, v.11, n. 4, p. 965-994, out./dez. 2011. 
projeto. Whiteley (1992) classifica os clientes em 3 tipos básicos, apresentados na Figura 2. Esta classificação é útil, pois a origem atribui características aos requisitos, como sua prioridade dentro do projeto.

Figura 2 - Tipos de clientes

\begin{tabular}{|c|c|c|}
\hline $\begin{array}{l}\text { Tipos de } \\
\text { Clientes }\end{array}$ & Descriçāo & $\begin{array}{c}\text { Exemplos no caso de uma empresa que desenvolve } \\
\text { projetos de edificaçóes. }\end{array}$ \\
\hline Finais & $\begin{array}{l}\text { São os consumidores e usuários finais do } \\
\text { produto. }\end{array}$ & $\begin{array}{l}\text { Proprietários de imóveis, moradores, a sociedade (devido ao } \\
\text { impacto da edificaçăo no meio ambiente e intervençăo no espaço } \\
\text { público). }\end{array}$ \\
\hline Internos & $\begin{array}{l}\text { Pessoas ou equipes internas da empresas } \\
\text { que desempenham funçốes ou } \\
\text { desenvolvem etapas específicas do projeto. }\end{array}$ & $\begin{array}{l}\text { Funcionários elou departamentos da empresa que desenvolve o } \\
\text { projeto. }\end{array}$ \\
\hline Intermediários & $\begin{array}{l}\text { Pessoas ou empresas enternas à } \\
\text { organização. }\end{array}$ & $\begin{array}{l}\text { Profissionais terceirizados como arquitetos, engenheiros, } \\
\text { empreiteira, fornecedores, corretores, órgäos governamentais, etc. }\end{array}$ \\
\hline
\end{tabular}

Fonte: Adaptado de Whiteley (1992)

Outro esclarecimento importante está relacionado à diferenciação entre demandas e requisitos. Demandas são as necessidades, desejos e restrições emitidas pelos clientes. É através delas que as empresas podem estabelecer os objetivos de um projeto e identificar as características que geram maior valor para os clientes MARX (2009). Já os requisitos, são transcrições das demandas em uma linguagem técnica (SOMMERVILLE, 2007; BRAY, 2002). São funcionalidades que o produto, ou serviço, devem ter para satisfazer uma necessidade ou alcançar objetivos dos clientes, quantificadas por condições mensuráveis e limitadas por restrições (PARVIAINEN; TIHINEN e VAN SOLINGEN, 2005). A tradução das demandas captadas para o formato de requisitos é importante para uma maior garantia de que toda a equipe de desenvolvimento irá interpretá-la da mesma forma (SOMMERVILLE, 2007). Segue abaixo um exemplo de transcrição de uma demanda no formato de requisito. É importante lembrar que é comum a necessidade de mais de um requisito para o atendimento integral de uma demanda (MARX, 2009).

Demanda: Adquirir um apartamento seguro.

Possíveis requisitos: O imóvel deve ser bem localizado; O imóvel deve ser dotado de sistemas de segurança; (...) 
Segundo autores como Kotonya e Sommerville (2000) e Young (2003), requisitos de boa qualidade devem ser necessários, intelegíveis, exeqüíveis, exatos, completos, testáveis, rastreáveis, exclusivos e não devem exigir soluções prematuras. Estas características são importantes, pois uma vez atendidas, garantem a qualidade da informação que irá entrar no projeto e gerar valor (YOUNG, 2003).

Tendo claros estes conceitos, pode-se partir para a análise das etapas ${ }^{1}$ da $\mathrm{GR}$, as quais, embora sejam encontradas com diferentes nomes (KOTONYA e SOMMERVILLE, 2000; BRAY, 2002; SOMMERVILLE, 2007), são apresentadas neste artigo como (i) identificação, (ii) análise e priorização, (iii) especificação e (iv) validação.

\subsection{Identificação}

Etapa de coleta e organização de informações dos clientes para a empresa entender o que é esperado do projeto (BRAY, 2002; SHEN et al., 2004; SOMMERVILLE, 2007) e identificar os requisitos a serem considerados. É necessário que todos os clientes sejam ouvidos para o completo entendimento sobre o que deve ser desenvolvido (SHEN et al., 2004). Alguns mecanismos para realizar - levantamento de informações que possam gerar requisitos são entrevistas, questionários, brainstorming, análise documental, workshops e análise conjunta (BRAY, 2002). Bray (2002) ainda observa que é importante que, primeiramente, haja um esforço na investigação do porquê da existência do projeto, através da identificação dos requisitos da própria empresa. Para ser competitiva é necessário atender simultaneamente aos requisitos dos clientes e aos requisitos internos da empresa, ligados ao seu planejamento estratégico (MÜLLER, 2003), pois eles servem de orientação.

\footnotetext{
1 Neste artigo a palavra "etapa" será relacionada às etapas da GR, enquanto a palavra "fase" será relacionada às fases do projeto. A convenção serve para facilitar a compreensão do texto.

Revista Produção Online. Florianópolis, SC, v.11, n. 4, p. 965-994, out./dez. 2011.
} 


\subsection{Análise e priorização}

A etapa de análise e priorização envolve a avaliação, organização e negociação dos requisitos (SOMMERVILLE, 2007). É comum que durante esta etapa sejam encontradas divergências devido a conflitos de interesse entre clientes (BARRET e STANLEY, 1999; KAMARA; ANUMBA; EVBUOMWAN, 2002; BRAY, 2002; SHEN et al., 2004; SOMMERVILLE, 2007). Cada um deles tem seus próprios requisitos e é necessário, através de trade-offs, encontrar um conjunto que possa resultar em um produto final com maior valor agregado (MIRON, 2002). Para que estes problemas sejam controlados, alguns autores propõe ferramentas para priorização (SHEN et al. 2004) e estimulam a adoção de práticas da gestão de stakeholders (WARD; CHAPMAN, 2008).

\subsection{Especificação}

A especificação é uma maneira de converter os requisitos em um comportamento (BRAY, 2002), de encontrar a solução funcional para eles serem atendidos. Esta etapa é muito importante por englobar uma série de decisões sobre o projeto (SOMMERVILLE, 2007). As soluções de projeto são elementos-chave na geração de valor e também exigem análise de trade-offs, uma vez que um requisito pode ser atendido de diferentes formas. Podem, inclusive, estimular mudanças no projeto (BRAY, 2002).

\subsection{Validação}

Bray (2002) afirma que a etapa de validação existe porque é necessário haver testes sobre os requisitos durante o desenvolvimento de projeto. A finalidade é evitar que problemas cheguem a fases mais avançadas. Está relacionada com a descoberta de problemas em tempo de corrigi-los evitando prejuízos e retrabalhos (SOMMERVILLE, 2007; SUN et al. 2005). A validação serve para certificar que o requisito está sendo atendido corretamente, conforme o especificado. Algumas das formas de realizar a validação são a prototipagem, testes e revisões com checklists 
(SOMMERVILLE, 2007). Requisitos consistentes devem ser testáveis (KOTONYA; SOMMERVILLE, 2000; YOUNG, 2003) e esta é uma das proeminentes dificuldades dos projetos de edificações, pois além de serem únicos, a elaboração de protótipos próximos à escala real e a execução de testes são possibilidades geralmente inviáveis. Possíveis de serem realizadas somente em alguns casos, ou com alguns componentes, como os pré-fabricados.

\subsection{Relação entre as etapas da GR}

Cada uma das quatro etapas apresentadas são, segundo Sommerville (2007), ciclicamente repetidas ao longo do projeto (Figura 3). As fases do projeto correspondem aos ciclos, nos quais os requisitos são identificados, analisados, priorizados, especificados e validados, pois o conjunto de requisitos se altera com o tempo. O acompanhamento permanente dos requisitos facilita o registro e controle das mudanças. Segundo Sommerville (2007), rastreabilidade é a propriedade de um requisito que reflete na facilidade de encontrar a sua origem e as relações para com os demais, ou seja, é possível saber quem o propôs, como este requisito evoluiu durante o desenvolvimento do projeto e o quanto outros requisitos poderão ser afetados por sua mudança. O rastreamento é feito na maioria das vezes pela atribuição de códigos, mas também podem ser utilizadas matrizes e figuras, dependendo da quantidade de requisitos, complexidade do projeto e ferramentas disponíveis (SOMMERVILLE, 2007). 
Figura 3 - Modelo em espiral das etapas da gestão de requisitos

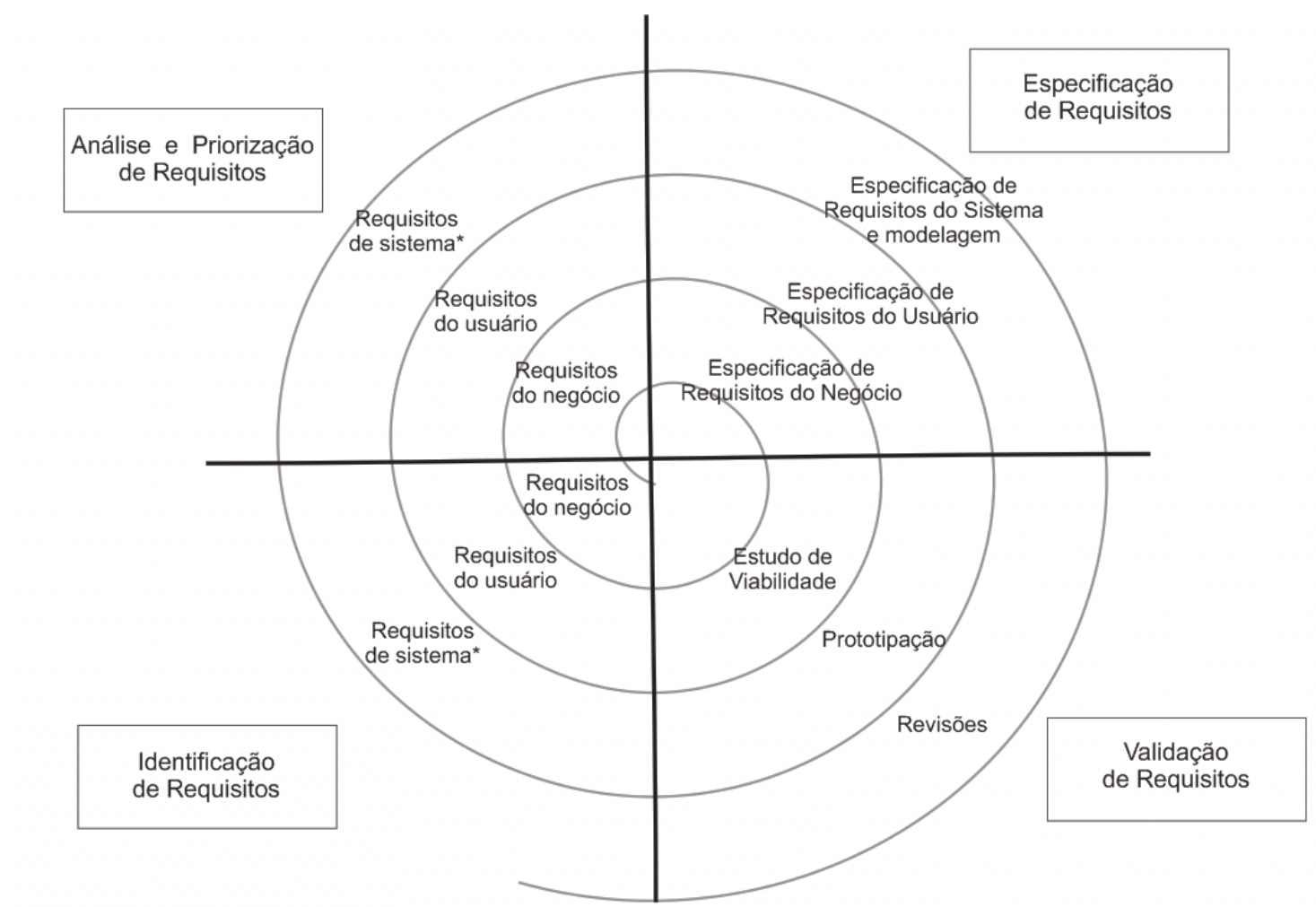

* A palavra "sistema" refere-se ao produto final e é usada devido à área de origem da figura: Engenharia de Software.

Fonte: Adaptado de Sommerville (2007)

Com estes esclarecimentos, pode-se perceber com mais clareza as contribuições que a GR pode trazer aos projetos de ambientes construídos. A seguir será discutido como tais contribuições ocorrem, ou poderiam ocorrer, na prática.

\section{MÉTODO DE PESQUISA}

As etapas da pesquisa estão representadas na Figura 4. Após a revisão teórica sobre os assuntos pertinentes, foi realizado um estudo de caso em uma empresa construtora, o qual permitiu que os pesquisadores analisassem, em um ambiente real, como a GP e a GR poderiam ser integradas.

A empresa do estudo de caso, Sigma, foi escolhida por possuir algumas características que permitiram uma abordagem objetiva acerca dos temas da pesquisa. Entre elas estão a estrutura gerencial bem organizada e um projeto formalizado. O estudo foi baseado em duas rodadas de entrevistas semiRevista Produção Online. Florianópolis, SC, v.11, n. 4, p. 965-994, out./dez. 2011. 
estruturadas, as quais foram gravadas e transcritas para posterior análise. Os entrevistados foram escolhidos em função do seu envolvimento no gerenciamento dos projetos da construtora, quais sejam: a gerente de produto, a gerente de projetos complementares e a gerente de planejamento de obras.

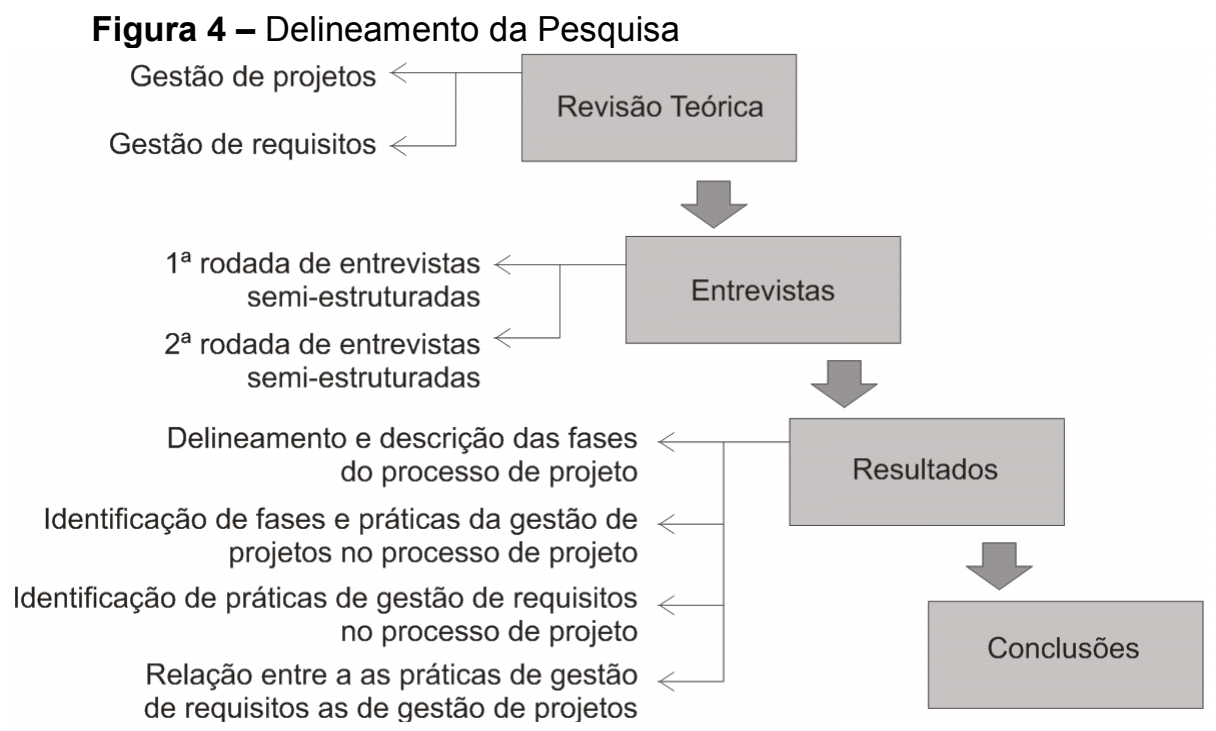

Os objetivos da primeira rodada de entrevistas foram: (i) identificar características gerenciais e funcionais da empresa para haver um entendimento sobre o ambiente onde seria desenvolvida a pesquisa, (ii) fazer um diagnóstico do projeto adotado pela empresa, pois a identificação e caracterização das principais fases, e respectivas atividades, envolvidos, entradas, saídas, são passos importantes para a investigação de abordagens de gerenciamento, (iii) identificar as fases e práticas da GP em tal processo, pretendendo investigar que benefícios trazem para a empresa.

$\mathrm{Na}$ primeira rodada foram feitas 2 entrevistas, uma delas com a gerente de produto, responsável pela concepção do empreendimento e desenvolvimento dos projetos arquitetônico e legal, e a outra com a gerente de projetos complementares, responsável pelo acompanhamento dos projetos complementares, como o hidrossanitário, elétrico, de ar-condicionado e de paisagismo. As entrevistas duraram aproximadamente 90 minutos e possuíam 20 questões, as quais estavam divididas em dois grupos. As do primeiro grupo examinaram as características da empresa (por exemplo: qual o ano de fundação, área de atuação, tipos de produtos, número de funcionários e descrição dos setores). Já as do segundo, buscaram informações

Revista Produção Online. Florianópolis, SC, v.11, n. 4, p. 965-994, out./dez. 2011. 
que permitissem o delineamento do projeto (duração, fases, envolvidos, gates, entre outros).

O diagnóstico do projeto da empresa foi realizado a partir da estruturação gráfica das fases citadas pelos entrevistados em paralelo às da GP. A estruturação ocorreu primeiramente de acordo com as semelhanças de propósito entre as fases, seguida pela ordenação das subfases e posicionamento dos gates, identificação dos principais envolvidos em cada uma das fases e, por fim, identificação das principais atividades, entradas e saídas de cada uma das fases. Os gates, representam os marcos gerenciais e técnicos dos projetos, que normalmente envolvem aprovações parciais e decisões importantes.

$\mathrm{Na}$ segunda rodada, foram investigadas iniciativas que poderiam estar relacionadas às práticas da $\mathrm{GR}$, como o uso de ferramentas ou existência de conhecimentos tácitos que pudessem ser analisados e aprimorados. Essa rodada envolveu 3 entrevistas semi-estruturadas, uma com cada uma das gerentes da primeira rodada, com o acréscimo da gerente de planejamento de obras. Estas entrevistas foram precedidas por uma breve explicação sobre a GR. Apresentavam aproximadamente 20 questões, tendo algumas variações devido à diferença de atividades exercidas pelos entrevistados. A gerente de produto, por exemplo, foi questionada sobre como eram levantados e priorizados os requisitos estratégicos do projeto, presentes nas fases iniciais e que envolviam a diretoria, acionistas e pesquisas de mercado, e que ferramentas eram utilizadas ao longo das fases sob sua responsabilidade. A gerente de projetos complementares discorreu sobre os requisitos dos projetistas complementares e sobre as frequentes incompatibilidades que surgem no projeto executivo. Já a gerente de planejamento de obras respondeu a questões mais específicas sobre os requisitos de obra, os quais devem ser considerados desde as fases anteriores à de obras.

Como a GR é ainda é um assunto pouco conhecido nas empresas deste setor, a abordagem dos entrevistados na segunda rodada evoluiu gradualmente, na medida em que os mesmos compreendiam os conceitos da GR. Neste sentido, a utilização de entrevistas semi-estruturadas foi vantajosa, pois se pode, aos poucos, revelar conhecimentos tácitos acerca do tema. 
As informações coletadas nos relatos, antes de serem analisadas, ainda foram classificadas segundo três critérios: (i) fase do projeto à que estavam relacionadas, (ii) ligação com práticas de GP e (iii) ligação com práticas de GR. Esta classificação facilitou a análise dos dados por já direcionar a informação ao tópico pertinente.

\section{RESUltados}

Este trabalho foi realizado em uma incorporadora e construtora de grande porte da cidade de Porto Alegre, presente no mercado há mais de 30 anos. A empresa Sigma em seu portfólio a construção e incorporação de mais de um milhão de metros quadrados, com mais de sete mil imóveis para habitação. Os empreendimentos são voltados para as classes $A$ e $B$, tendo, porém, tipologias e aspectos formais variados de acordo com o público alvo específico de cada empreendimento.

\subsection{Delineamento e descrição das fases do projeto}

Como resultado das informações da primeira rodada de entrevistas, foi delineado o formato de um projeto genérico da empresa, o que permitiu a compreensão das suas fases, atividades e principais envolvidos. A Figura 5 foi obtida a partir do procedimento descrito no método de pesquisa e aprovada pela gerente de produto. Representa a síntese do projeto, tendo suas fases colocadas em paralelo às fases da GP para a realização da análise.

\subsubsection{Macrofase 01 - Incorporação}

Envolve definições importantes realizadas pela diretoria, principais acionistas e altas gerências. Este grupo analisa o portfólio de projetos frente às demandas, possibilidades de terrenos e objetivos estratégicos da empresa. Possui como principal gate a escolha do terreno e a definição do caráter do empreendimento, o 
que envolve a decisão das principais características, do público alvo e do estilo arquitetônico do edifício, por exemplo.

As fases 1.1 e 1.2 podem ocorrer em ordem inversa, pois tanto uma demanda pode deliberar a compra de um terreno, como um terreno com bom potencial pode ser comprado para a posterior concepção de um projeto específico para ele. $\mathrm{Na}$ macrofase de incorporação são adotadas medidas de prevenção de riscos como a realização de ensaios para a verificação da condição geológica, análise da vegetação e das leis aplicáveis aos terrenos. Além disso, também nesta fase são esboçados cronogramas de longo prazo e pré-estabelecidas as equipes que trabalharão no projeto.

\subsubsection{Macrofase 02 - Desenvolvimento do Projeto}

Após ser feita a escolha do terreno e caráter do empreendimento, no segundo gate gerencial, é iniciada a fase de desenvolvimento do projeto, coordenada pela gerente de produto. Durante o estudo preliminar, ainda existe uma série de definições, como a área privativa dos apartamentos, quantidade de vagas para veículos, tipos de usos para áreas condominiais e tecnologias construtivas a serem adotadas. Muitas vezes, nesta fase o terreno ainda não foi comprado, pois pode haver incerteza acerca de informações geradas na macrofase anterior. É nesta fase também que são elaborados cronogramas e estabelecidas as atividades e responsabilidades dos envolvidos. 
Figura 5 - Fases dos projetos da empresa Sigma e relações com as fases da GP

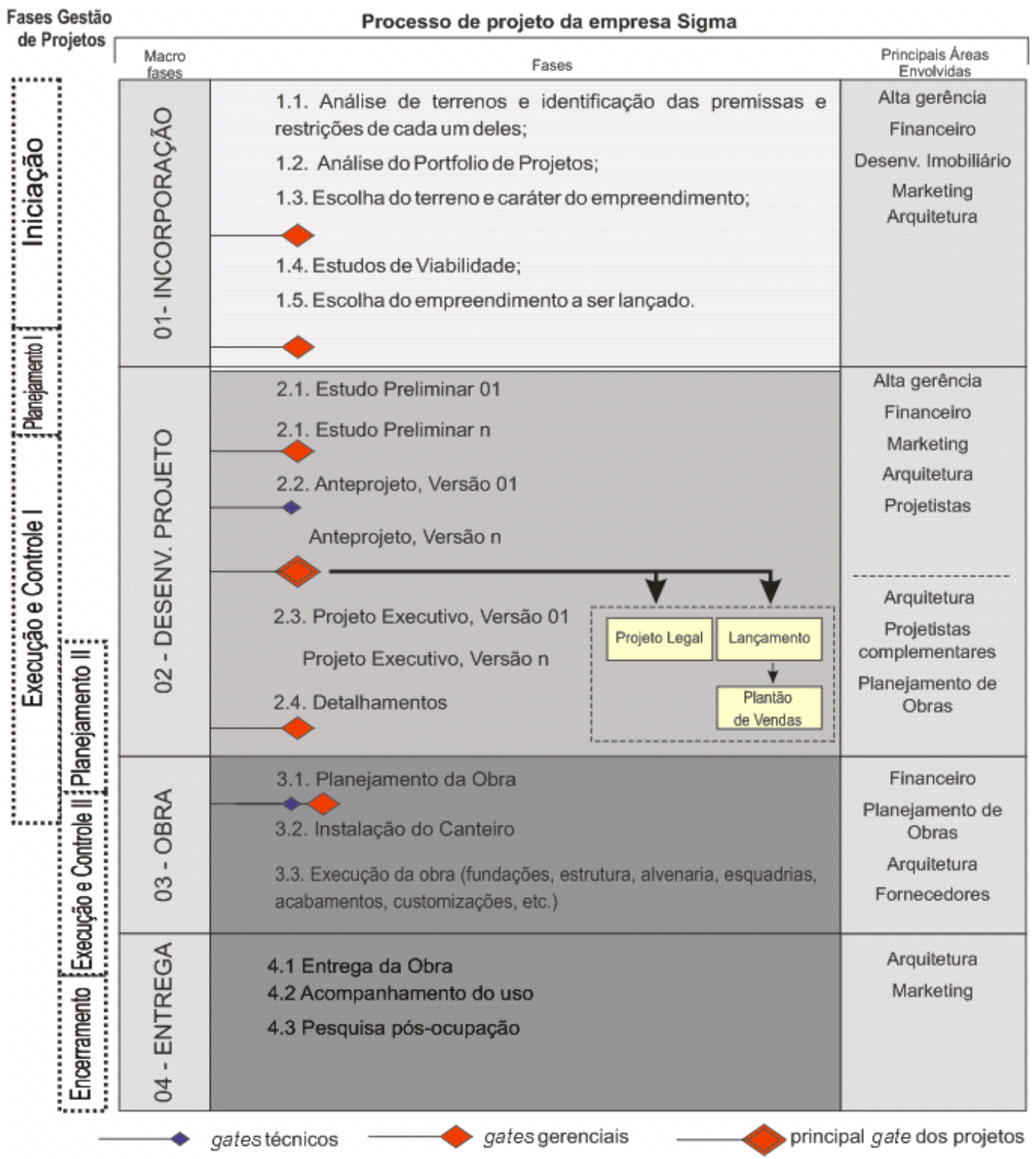

Após a definição da tipologia do empreendimento, que envolve a definição de questões como número de pavimentos, quantidade de apartamentos por andar e área construída aproximada, por exemplo, é autorizado, pela diretoria, o início da fase de anteprojeto, que inclui o desenvolvimento de plantas, cortes e fachadas.

Neste momento, as gerentes dos projetos arquitetônicos, que gerenciam mais de um projeto, coordenam uma equipe que os desenvolve em profundidade fazendo definições mais precisas de dimensões dos compartimentos, esquadrias, configuração da fachada, usos dos espaços condominiais, atendimento efetivo da

Revista Produção Online. Florianópolis, SC, v.11, n. 4, p. 965-994, out./dez. 2011. 
legislação e também iniciam a integração do projeto arquitetônico com os projetos complementares, terceirizados, a fim de já pré-dimensionar os espaços necessários para as instalações e estrutura. Foi enfatizado pelos entrevistados, que, pelo fato do grupo de projetistas envolvidos nos projetos já trabalharem juntos há anos, existem práticas já consolidadas. Elas são manifestadas, por exemplo, nas formas de comunicação, troca de informações e nos tipos de soluções de projeto adotadas. Isto facilita as soluções de problemas e incompatibilidades, e traz melhorias para projetos futuros diante das lições aprendidas em conjunto.

O segundo gate gerencial da macrofase de desenvolvimento do projeto é o principal marco do mesmo. Após terem sido feitas todas as principais definições de questões funcionais, estéticas e financeiras, é realizada uma reunião com representantes de todas as áreas da empresa a fim de decidir se o projeto vai ser lançado no mercado, ou se ainda precisa de melhorias. Uma vez aprovado, além de passar para a fase de projeto executivo e detalhamentos, quando é consolidada a integração com os projetos complementares, é preparado o projeto legal, a ser aprovado pela prefeitura. Simultaneamente ao início do projeto legal, ocorre o processo de lançamento do empreendimento, envolvendo com intensidade a área de marketing.

\subsubsection{Macrofase 03 - Obra}

Uma vez que sejam encerrados os detalhamentos e o projeto esteja aprovado na prefeitura, a obra pode ser iniciada. Contudo, é comum que a preparação do canteiro de obras e a execução de fundações iniciem antes da finalização dos detalhamentos. Na fase de produção, o produto da construção civil possui algumas características intrínsecas: não é passível à produção em larga escala, tem longo ciclo de produção, forte fragmentação e heterogeneidade de fornecedores e clientes internos e há dificuldades em fazer prototipagens (FABRICIO, 2002). Para auxiliar no gerenciamento desta macrofase, existe um gerente e um setor específico para o planejamento de obra, responsáveis pela logística do canteiro, sequência de atividades e cronogramas. Este setor conta com o apoio de engenheiros e técnicos 
que trabalham na obra, os quais coletam informações, além de controlarem e fiscalizarem as atividades previstas.

\subsubsection{Macrofase 04 - Entrega}

A macrofase de encerramento do projeto ocorre ao longo das entregas dos apartamentos. Nessa fase, além de serem feitos os últimos ajustes nos acabamentos e encerramentos de contratos, é realizado o acompanhamento do uso, quando a empresa coleta informações sobre todo o andamento do projeto e registra as lições aprendidas para retroalimentar os próximos projetos. Com o mesmo intuito, após alguns meses é feita a avaliação pós-ocupação (APO) visando identificar o nível de satisfação, e quais requisitos, que atendidos ou não, causaram maior impacto na opinião dos clientes finais.

\subsection{Identificação de fases e práticas da GP de ambientes construídos}

Com base na descrição das fases do projeto, percebeu-se que os objetivos e saídas de cada fase são bem definidos, assim como a posição dos gates e as atribuições dos envolvidos. Por ser uma construtora de grande porte, com 9 setores e 12 projetos em andamento, percebeu-se a preocupação, mesmo que demonstradas de formas pontuais nas entrevistas, com todas as nove áreas de conhecimento citadas na bibliografia de GP. A exemplo cita-se (i) a definição criteriosa do escopo do projeto com base nas pesquisas de mercado e interesses dos principais envolvidos (gestão do escopo), (ii) as análises de risco (gestão de reiscos), (iii) o monitoramento dos prazos das atividades, por meio dos cronogramas e realização medições (gestão do tempo), (iv) o uso de extranet para troca de informações entre os envolvidos e controle sobre versões do projeto (gestão da comunicação), (v) registro dos erros através de relatórios e documentação das mudanças (gestão do escopo), (v) avaliação dos profissionais envolvidos (gestão de recursos humanos).

Estas iniciativas representam importantes contribuições, pois esclarecem informações importantes, possibilitam o controle sobre o andamento do projeto e Revista Produção Online. Florianópolis, SC, v.11, n. 4, p. 965-994, out./dez. 2011. 
favorecem o desenvolvimento do grupo de profissionais. O registro dos erros, lições e avaliações dos envolvidos ao longo do projeto são exemplos de fontes de aprendizado, as quais trazem benefícios a todos.

Ao longo das fases do projeto foram percebidas as características da GP citadas por Keeling (2002) e Meredith e Mantel Jr. (2002) como desmembramento dos processos em atividades, foco nos objetivos, interdependências com atividades de rotina e medição dos processos (especialmente na obra). Destaca-se também a constatação da existência de duas fases de planejamento, e controle e execução, as quais, inclusive, são coordenadas por gerentes diferentes. Em relação a este aspecto, as entrevistadas defenderam que é comum que as fases de design do edifício sejam planejadas e executadas separadamente das fases de produção sob a justificativa de que envolvem capacitação, atividades e equipes diferentes. Além disso, o início das fases de design é separado do início da obra por aproximadamente oito meses. Contudo, há uma dificuldade associada a esta prática, pois a fragmentação do planejamento tende a criar lacunas na concepção do projeto, pois limitações de canteiro e dificuldades na obra podem interferir no design.

Outra característica que merece ser destacada é estrutura organizacioal da empresa, a qual se assemelha à estrutura do tipo funcional proposta por Ulrich e Eppinger (2000). Existe um gerente geral de todos os projetos, a qual coordena os gerentes funcionais, que, por sua vez, são responsáveis por determinadas etapas e/ou funções dentro do projeto (Figura 6).

Figura 6 - Estrutura da empresa

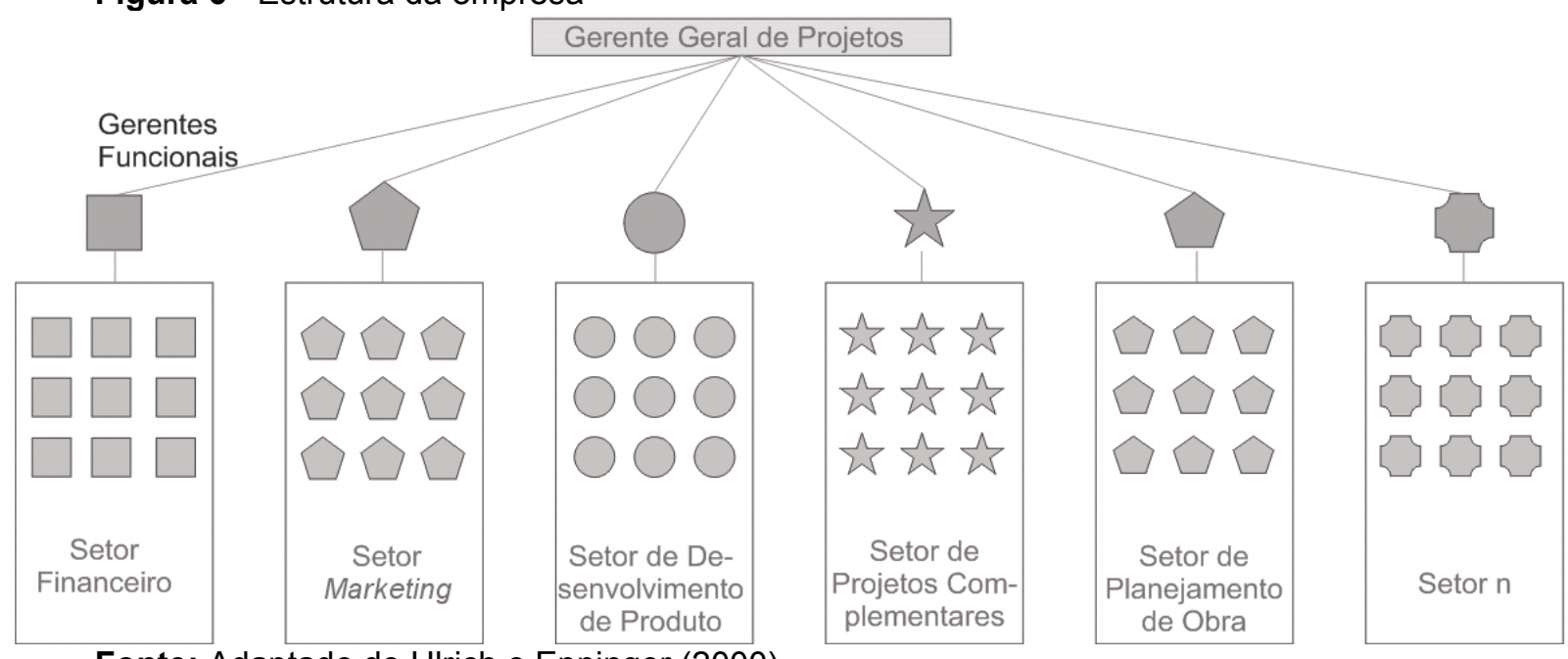

Fonte: Adaptado de Ulrich e Eppinger (2000)

Revista Produção Online. Florianópolis, SC, v.11, n. 4, p. 965-994, out./dez. 2011. 
Esta estrutura não é considerada a mais favorável para a GP, pois, o projeto não possuiu uma pessoa responsável por todo o seu desenvolvimento e é comum que neste formato existam dificuldades como falhas de comunicação e de registro de informações e pouca disseminação das lições aprendidas (ULRICH; EPPINGER, 2000). No entanto, a forte estrutura do projeto, a ligação coesa entre os gerentes funcionais, o uso de tipologias e tecnologias construtivas já consolidadas, e a boa comunicação, por vezes informal, entre os envolvidos fazem com que, na prática, a estrutura funcional não seja tão rígida, superando algumas barreiras deste modelo.

Este ponto, acrescido dos aproximados cinco anos de experiência conjunta do grupo de projetistas, emerge uma discussão acerca dos prós e contras das informalidades. Pelo que se viu na prática, a comunicação informal e algumas maneiras tácitas de conduzir a gestão do projeto podem funcionar adequadamente, se dentro desta informalidade existirem regras e entrosamento entre os envolvidos.

Assim, é importante que as propostas de novas práticas, que pretendem superar problemas, sejam suficientemente flexíveis para que as informalidades benéficas de cada empresa sejam consideradas e, se conveniente, formalizadas.

\subsection{Identificação das fases e práticas de GR nos projetos}

O primeiro passo para a identificação das práticas de GR foi compreender quais eram os envolvidos no projeto para, em seguida, investigar como suas demandas e requisitos tendem a ser considerados no desenvolvimento dos projetos. A Figura 7 explicita alguns clientes identificados no estudo de caso, classificados de acordo com Whiteley (1992).

Revista Produção Online. Florianópolis, SC, v.11, n. 4, p. 965-994, out./dez. 2011. 
Figura 7 - Exemplos de clientes envolvidos nos projetos da empresa e exemplos de requisitos

\begin{tabular}{|l|l|l|}
\hline \multicolumn{2}{|c|}{ Categoria de Clientes } & \multicolumn{1}{c|}{ Exemplos de Requisitos } \\
\hline \multirow{4}{*}{ Internos } & Diretoria & O edifício deve ter padrão de acabamento classe A. \\
\cline { 2 - 4 } & Departamento de Marketing & O empreendimento deve ter ampla área esportiva. \\
\cline { 2 - 4 } & Departamento de arquitetura & Os dormitórios devem ser ensolarados. \\
\cline { 2 - 4 } & Departamento de projetos complementares & $\begin{array}{l}\text { As tubulaçóes de gás devem passar em shafts isolados de } \\
\text { outras instalações. }\end{array}$ \\
\hline \multirow{3}{*}{$\begin{array}{l}\text { Interme- } \\
\text { diários }\end{array}$} & Projetistas de instalações & $\begin{array}{l}\text { A área para o reservatório de água inferior deve ser suficiente } \\
\text { para a realização da manutenção dos equipamentos. }\end{array}$ \\
\cline { 2 - 4 } & $\begin{array}{l}\text { Equipes de obra (operários, engenheiros de } \\
\text { obra, técnicos em edificações) terceirizadas }\end{array}$ & $\begin{array}{l}\text { Os materiais de construção devem permanecer em locais } \\
\text { protegidos da chuva. }\end{array}$ \\
\cline { 2 - 4 } & Imobiliárias & $\begin{array}{l}\text { Os apartamentos devem ter um preço de venda abaixo de } \\
\text { R\$400.000,00. }\end{array}$ \\
\hline \multirow{2}{*}{ Final } & Público alvo & O empreendimento deve ter ampla área de lazer. \\
\cline { 2 - 4 } & Sociedade em geral & As vegetação que interfere no espaço público deve ser mantida. \\
\hline
\end{tabular}

Na Figura 7 percebe-se que os clientes podem emitir requisitos de diferentes níveis hierárquicos, visto que, enquanto alguns se referem a questões estratégicas do projeto, outros se referem a questões operacionais. Um requisito estratégico da diretoria, como o "o edifício deve ter padrão de acabamento classe A", por exemplo, é amplo e acompanha o projeto desde a incorporação, devendo ser desdobrado ao longo das fases em requisitos mais específicos, que englobam itens como materiais, tecnologias construtivas, mão-de-obra, entre outros. Sua modificação provavelmente causa mais impacto em outros requisitos, e no projeto como um todo, do que se houver mudança em um requisito mais específico ou tardio, relacionado à escolha de um tipo de tinta, por exemplo.

Mesmo havendo algumas boas práticas como a retroalimentação pelo feedback de outros projetos, o registro de erros e a boa comunicação entre os projetistas, percebeu-se que a etapa de identificação é limitada. Um exemplo claro desta limitação é a existência de duas fases de planejamento (Figura 5). Esta dissociação dificulta a consideração de requisitos de obra (ligados à logística e à segurança do trabalho, por exemplo) durante o desenvolvimento do projeto.

Além disso, nas etapas de identificação deveria ser feita uma coleta de informações mais aprofundada junto aos envolvidos, e não somente com os clientes finais. Embora a maior prioridade dos requisitos dos clientes finais possa ser uma estratégia da empresa, os requisitos de clientes intermediários e internos devem ser

Revista Produção Online. Florianópolis, SC, v.11, n. 4, p. 965-994, out./dez. 2011. 
melhor considerados. Estes clientes emitem requisitos fundamentais (como os técnicos, estéticos, funcionais e financeiros) que, por vezes, podem não ser percebidos pelo cliente final, mas são fundamentais para a satisfação do mesmo.

Outro possível efeito da pouca consideração dos requisitos dos clientes internos e intermediários no início do processo é a ocorrência de retrabalhos e na insatisfação entre parceiros.

Em relação aos requisitos dos clientes internos, dos setores da empresa, foi diagnosticada a prioridade dos departamentos de marketing e financeiro, além da área de alta gerência, devido à ênfase nas entrevistas. O motivo é o de que eles têm requisitos mais ligados ao planejamento estratégico e questões voltadas à lucratividade dos empreendimentos.

Durante as entrevistas, também foi percebida pouca preocupação em tornar os requisitos claros e bem definidos, como sugerido por Bray (2002), Kotonya e Sommerville (2000), Young (2003), e tampouco uma forma de estabelecimento de ligações claras com as estratégias da empresa. De fato, os primeiros requisitos de um projeto devem ser provenientes da própria empresa e não de agentes externos. Eles devem estar claramente definidos por serem determinantes tanto à GP, quanto à $G R$, pois norteiam a alta ou baixa prioridade dos demais requisitos e das atividades a seu atendimento.

Assim, as iniciativas de GR identificadas no estudo de caso são de pouca significância, se comparadas às possíveis melhorias. Os requisitos são identificados, analisados, priorizados e especificados tacitamente ao longo do projeto, não havendo método, ferramentas para o rastreamento, o controle da mudança ou a análise detalhada das relações entre eles e desdobramentos.

\subsection{Relação entre a as práticas de GR e as de GP}

Um ponto importante a ser apresentado, verificado ainda na revisão teórica, é de que as práticas de GP aplicam-se a distintas áreas de conhecimento (escopo custos, riscos, qualidade, etc.). Portanto, ela trata do assunto da mudança de requisitos de forma genérica, considerando algumas práticas como os documentos de controle de mudanças de escopo. A GR, por sua vez, trata das mudanças de 
forma específica através de métodos formais e estruturados. A razão disso pode residir no fato de que no desenvolvimento de softwares, área onde a GR mais se desenvolveu, frequentemente existe customização e o cliente tem forte poder decisório e de influência, entre outros aspectos similares aos projetos da construção.

$\mathrm{Na}$ prática, com base nas análises realizadas durante o estudo de caso, foi possível identificar pontos positivos e negativos nos procedimentos adotados pela empresa estudada tanto sob a ótica da GR, quanto da GP. Alguns desses pontos são comuns a ambos os casos. O registro de mudanças e controle de versões, por exemplo, são práticas importantes para as duas abordagens, visto que são atividades básicas da $\mathrm{GR}$, que contribuem para a gestão do escopo, qualidade e do tempo. Já do ponto de vista negativo, a falta de um método para identificação de requisitos de todos os clientes nas diversas fases do projeto é um problema que pode trazer dificuldades às duas abordagens: se por um lado compromete todo o processo de GR, devido à incompleta coleta de requisitos, por outro interfere em pontos críticos da GP, entre eles uma determinação acertada do escopo.

As atividades da GR, em geral, podem trazer vantagens à GP devido à atualização contínua dos requisitos do projeto. Uma vez que controla e rastreia os requisitos, a GR age como um apoio ao permitir que todos os envolvidas tenham uma visão clara acerca das relações e das decisões. Neste sentido, atua como uma aliada na gestão da integração.

Contudo, como algumas atividades da GR são semelhantes a outras já tradicionais da GP, como a identificação de requisitos a partir de demandas, o registro e detalhamento dos requisitos, a análise das mudanças de projeto para não perder o foco no escopo, se não houver uma ação integrada entre as abordagens, é possível que ocorra uma repetição de atividades nos dois processos. Esta repetição potencializa $\circ$ desperdício de tempo, conflitos entre informações e, consequentemente, erros e retrabalhos. Portanto, a integração efetiva da GR à GP é essencial para evitar estes riscos. Pode ser feita através da unificação de documentos, bases de dados, e da capacitação dos profissionais envolvidos.

Com a realização das entrevistas pode-se também entender como as fases da GR se conectam com as fases do projeto. Neste aspecto, verificou-se que a GR deve ser realizada ciclicamente ao longo do projeto, conforme proposto por Revista Produção Online. Florianópolis, SC, v.11, n. 4, p. 965-994, out./dez. 2011. 
Sommerville (2007) na Figura 3. Os requisitos passam pelas quatro etapas da GR ao longo dos projetos. Para ilustrar esta análise, foi elaborada a Figura 8. Ao final de cada ciclo é desejável que os requisitos do projeto estejam atualizados, priorizados, especificados e validados de forma clara e compatível aos interesses dos clientes.

Para isso é necessária a utilização de ferramentas como planilhas, matrizes e estruturas gráficas. Estas ferramentas devem permitir o rastreamento dos requisitos a fim de possibilitar a visualização de sua origem e de seus desdobramentos.

Figura 8 - Relação das etapas da GR com as fases dos projetos

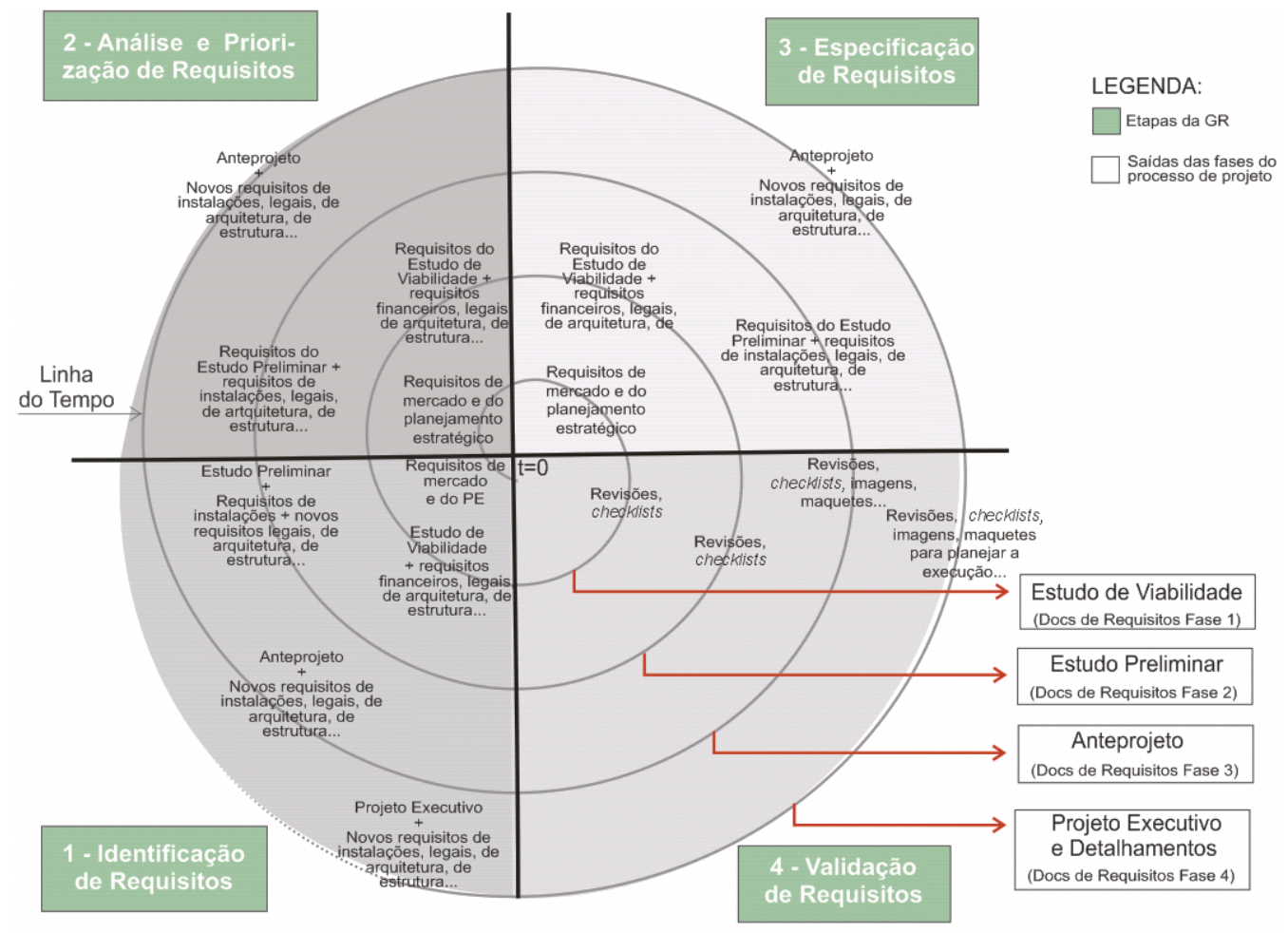

Para realizar uma boa GR é recomendável que, quando identificados, os requisitos sejam classificados de acordo com a origem e fase onde deve ser considerado (analisado, priorizado, especificado e validado). A classificação de requisitos, que ocorre na etapa de análise e priorização, é uma dificuldade eminente, para a qual ainda precisam ser desenvolvidos métodos e ferramentas de apoio. A adequada análise contribui para a escolha de requisitos mais importantes e para a tomada de decisão frente a situações de conflitos. 
Ao observar a Figura 8 fica evidenciada a importância de haver um projeto estruturado para a realização das atividades da GR. Tal estruturação consiste na organização clara e documentada das fases do projeto, e na identificação das principais atividades, envolvidos, entradas e saídas de cada uma delas. A estruturação é uma condicionante para o sucesso na aplicação das práticas da GR.

Diante destes resultados, entende-se que as práticas de GR ora apresentadas podem atuar como reforços na gestão da mudança, uma das carências identificadas na GP de ambientes construídos. Os benefícios oferecidos pela GR não atendem plenamente às nove áreas de conhecimento existentes (gestão do escopo, tempo, custos, comunicação, riscos, recursos humanos, aquisições, qualidade e integração), mas podem trazer importantes contribuições. Por exemplo: (i) alinhamento os requisitos dos clientes aos da empresa (gestão do escopo); (ii) controle as mudanças e prevenção de retrabalhos (gestão do tempo, custos, riscos, qualidade); (iii) melhorias para a comunicação entre os envolvidos (gestão da comunicação, tempo, riscos).

Deve-se ainda salientar que a realização das quatro etapas do ciclo da GR é importante para que a mesma seja efetiva. Esta observação é especialmente importante nos primeiros ciclos, durante a iniciação do projeto, quando devem ser definidos os requisitos estratégicos, que atuam como norteadores dos demais.

\section{CONCLUSÕES}

As primeiras conclusões sobre as similaridades e diferenças das práticas de GR e GP foram aparentes desde a revisão teórica, quando se compreendeu que algumas boas práticas de GR estavam presentes na GP de forma pulverizada. No entanto, para preencher a lacuna apontada no problema de pesquisa conclui-se que era importante estreitar as relações entre estas duas abordagens e encontrar práticas para melhor gerenciar os requisitos dos projetos e suas mudanças.

$\mathrm{Na}$ comparação do objetivo desta pesquisa frente ao que se viu na prática, percebeu-se que a colocação da GR como um processo de apoio à GP pode trazer benefícios, pois é complementar em alguns aspectos. A GR acontece em um projeto, mesmo que de forma desorganizada e tácita, pois os requisitos precisam Revista Produção Online. Florianópolis, SC, v.11, n. 4, p. 965-994, out./dez. 2011. 
existir para que o projeto seja concebido. Assim, a iniciativa de gerenciá-los com a utilização de práticas consolidadas e de controlar suas mudanças pode trazer bons resultados para as empresas que desenvolvem projetos de ambientes construídos.

Concluiu-se também que uma adequada estruturação do projeto é uma premissa para a GR, pois esta abordagem necessita de um ambiente bem preparado para que seja efetiva. Ainda, percebeu-se a relevância da etapa de identificação, uma vez que define as informações de entrada do projeto, ou seja, determina quais requisitos entrarão no espiral e serão transformados em um produto final.

Por fim, observou-se que, de fato, a GR é uma disciplina ainda pouco explorada tanto na teoria quanto na prática. A falta de conhecimento sobre o tema, identificada no estudo de caso, pode ser reflexo da falta de propostas de diretrizes e práticas dinâmicas, que possibilitem o acompanhamento dos requisitos ao longo dos projetos. Como sugestão de trabalhos futuros, recomenda-se que as atividades das etapas da GR sejam aprofundadas, e aplicadas em outros cenários. O objetivo é o de detalhar e validar a proposta de integração apresentada na Figura 8, e obter conclusões baseadas em outros casos sobre as vantagens e desvantagens da integração a GR com a GP.

\section{REFERÊNCIAS}

ATKINSON, R.; CRAWFORD, L. e WARD, S. Fundamental uncertainties in project and scope of project management. International Journal of Project Management. v.24, p. 687-698, 2006.

BARRET, P.S; STANLEY, C.A. Better construction briefing. Blackwell Science, 1999.

BRAY, I.K. An Introduction to Requirements Engineering. Pearson Education Limited. UK, 2002.

FABRÍCIO, M. M. Projeto simultâneo na construção de edifícios. Tese (Doutorado em Engenharia Civil e Urbana). Escola Politécnica,USP, São Paulo, 2002.

GUSMÃO, I. F.; CÂNDIDO, A. P.; HERMENEGILDO, J. L. S. A gestão de projetos nas organizações: o gerente de projetos como pessoa-chave. Disponível em 
http://npdeweb.cefetsc.edu.br/conteudos/upload/artigo/15101818082006.pdf. Acesso em: 05 dez. 2009.

HUOVILA, P. Organisation\&management. Technical Research Centre of Finland, VTT, 2005.

KAMARA, J. M.; ANUMBA, C. J.; EVBUOMWAN, N. F. Capturing client requirements in construction projects. American Society of Civil Engineers;Thomas Telford Ltd. 2002

KEELING, R. Gestão de projetos: uma abordagem global. São Paulo: Saraiva, 2002.

KERZNER, H. Gestão de projetos: as melhores práticas. Porto Alegre: Bookman, 2002.

KOTONYA, G.; SOMMERVILLE, I. Requirements engineering: process and techniques. Chichester: John Wiley \& Sons, 2000.

MARX, A.M. Proposta de método de gr para o desenvolvimento de produtos sustentáveis. Dissertação (Mestrado em Engenharia de Produção). PPGEP, UFRGS, 2009.

MELHADO, S.B. Coordenação de projetos de edificações. São Paulo: O nome da Rosa, 2005.

MEREDITH, J. R.; MANTEL JR., S.J. Project management: a managerial approach. 5.ed. New York: Jonh Wiley \& Sons, 2002.

MIRON, L. I. G. Proposta de diretrizes para o gerenciamento dos requisitos do cliente em empreendimentos da construção. Dissertação (Mestrado em Engenharia Civil). NORIE, UFRGS, 2002.

MIRON, L. I. G. Gerenciamento de requisitos dos clientes de empreendimentos habitacionais de interesse social: proposta para o programa integrado entrada da cidade em Porto Alegre - RS. Tese (Doutorado em Engenharia Civil). NORIE, UFRGS, 2008.

MÜLLER, C. J. Modelo de gestão integrando planejamento estratégico, sistemas de avaliação de desempenho e gerenciamento de processos (meio modelo de estratégia, indicadores e operações). Tese (Doutorado em Engenharia de Produção) PPGEP, UFRGS, 2003.

PARVIAINEN, P.; TIHINEN, M.; VAN SOLINGEN, R. Requirements engineering: dealing with the complexity of Sociotechnical Systems Development. In: MATÉ, J. L.; SILVA, A. Requirements engineering for sociotechnical systems. Hershey: Information Science Publishing, 2005. cap. 2. 
PATAH, L. A.; CARVALHO, M. M. Estruturas de gerenciamento de projetos e competências em equipes de projetos. In: ENCONTRO NACIONAL DE ENGENHARIA DE PRODUÇÃO, Curitiba, 22, 2002. Anais... Porto Alegre: ABEPRO, p. 1-8, 2002.

PEKTAS, S.T.; PULTAR M. Modelling detailed information flows in building design with the parameter-based design structure matrix. Design Studies. Londres, v.27, 122, 2006.

PROJECT MANAGEMENT INSTITUTE (PMI) - Um Guia do conjunto de conhecimentos em gerenciamento de projetos (Guia PMBOK®). $3 \mathrm{Ed}$. Project Management Institute, 14 Campus Boulevard, Newtown Square, PA EUA. 2004.

ROMANO, F.V. Modelo de referência para o gerenciamento do processo de projeto na construção civil. Tese (Doutorado em Engenharia de Produção). PPGEP, UFSC, 2003.

SHEN, Q.; LI H.; CHUNG, J.; HUI, P. A framework for identification and representation of client requirements in briefing process. Construction management and economics, v. 22, 2004.

SOMMERVILLE, I. Engenharia de software. São Paulo: Pearson Addion-Wesley, 2007.

SUN, M. et al. Managing changes in construction project. UWE: Bristol, 2005. Disponível em <http://www.builtenvironment.uwe.ac.uk/research/cprc/publications/mcd.pdf>. Acesso em: 14 nov. 2009.

TURNER, J.R. Evolution of project management research as evidenced by papers published in the International Journal of Project Management. International Journal of Project Management, v.28, p. 1-6. 2010.

TZORTZOPOULOS, P. Contribuições para o desenvolvimento de um modelo do processo de projeto de edificações em empresas construtoras incorporadoras de pequeno porte. Dissertação (Mestrado em Engenharia Civil). NORIE, UFRGS, 1999.

TZORTZOPOULOS, P. The design and implementation of product development process models in construction companies. Tese (Engenharia Civil). University of Salford, Salford, UK, 2004

ULRICH, K.T; EPPINGER S.D. Product and design development. 2 ed. Irwin McGraw-Hill, 2000.

WARD, S; CHAPMAN, C. Stakeholders and uncertainty management in projects.

Construction Management and Economics, v. 26, n. 6, 2008. 
WHITELEY, R.C. A empresa totalmente voltada para o cliente Rio de Janeiro: Campus, Publifolha, 1999.

WIEGERS, K.E. Software requirements. 2 Ed. Microsoft Press, 2003.

YOUNG, R. The requirements engineering handbook. Norwood: Artech House, 2003. Disponível em:

$<$ http://site.ebrary.com/lib/ufrgs/docDetail.action?doclD=10081936>. Acesso em: 10 jun. 2009.

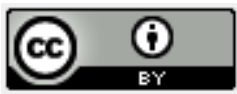

Artigo recebido em 12/04/2010 e aceito para publicação em 20/11/2011.

Revista Produção Online. Florianópolis, SC, v.11, n. 4, p. 965-994, out./dez. 2011. 